\title{
Pharmacokinetics Analysis of Copen, a Novel Antitumor Semi Synthetic Derivative of Osthole, in Rats after Intragastric and Intravenous Administration
}

\author{
Zheng $\mathbf{Y}^{1}$, Zhou $\mathbf{H}^{1}$, Hu $\mathbf{X}^{1}$, Wu $\mathbf{G}^{1}$, Yanan $\mathrm{L}^{2}$ and Shentu $\mathbf{J}^{1^{*}}$ \\ ${ }^{1}$ Research Centre for Clinical Pharmacy, State Key Laboratory for Diagnosis and Treatment of Infectious Diseases, First Affiliated Hospital, Zhejiang University, Hangzhou \\ 310003, China \\ ${ }^{2}$ Guangdong Zonk Drug R\&D Limited, Guangdong, Guangzhou, 510730, China
}

\begin{abstract}
Copen is one of the major semi synthetic derivatives of osthole with obvious antitumor activity. The absolute bioavailability and gender-related pharmacokinetic properties of copen in rats were determined in this study. Sprague-Dawley rats were intragastrically and intravenously administrated of different doses of copen, respectively. The concentrations of copen in rat plasma were determined by a LC-MS/MS method. Pharmacokinetic parameters were estimated using a drug and statistics (DAS) software. Statistical analysis was performed using independent two-sample t-test with $p$-values less than 0.05 as the level of significance. The results indicated that maximum plasma concentrations $\left(C_{\max }\right)$ for copen were achieved at 9.17-14.17 min post-intragastric dosing; the elimination half-life $\left(\mathrm{t}_{1} / 2_{z}\right)$ of copen after intragastric dosing was 196.55-302.16 min. After intragastric administration of copen, the spearman's rank correlation coefficient $(r s)$ of $C_{\max }$-Dose was $0.49810(p=0.0023)$, and the rs of $A U C_{0 . t}$-Dose was $0.74634(p<0.0001)$. Significant differences $(p<0.05)$ of $A U C_{0-1}, A U C_{0-\infty}, C L z / F$ and $C_{\max }$ were present in female and male groups after intragastric doses. Absolute bioavailability of copen was assessed to be ranged from 2.21$10.67 \%$ for different doses in rats. The pharmacokinetic properties of copen in rat were characterized as rapid oral absorption, slow clearance, and significant gender differences.
\end{abstract}

Keywords: Pharmacokinetics; Absolute bioavailability; Gender difference; Copen

\section{Introduction}

Nowadays, the active compounds from Traditional Chinese Medicine (TCM) have attracted more and more attention. Osthole (Figure 1) is a major bioactive ingredient isolated from Cnidium monnieri (L.) cusson $[1,2]$, which has been used for treatment of pain in female genitalia, impotence, and suppurative dermatitis (as an antipruritogenic agent). Osthole exhibits various pharmacological activities, including in vitro/in vivo antitumor effects [3-8], alleviation of hyperglycemia and hypolipidemia $[9,10]$, and has been proposed the possibility of its development as a promising lead compound for drug discovery [11,12]. However, the clinical utility of this phytochemical is limited due to its low bioavailability in vivo [13-16], and some structural modifications are required for sufficient bioavailability upon oral administration. Copen (Figure 1) is a semi synthetic derivative of osthole obtained by structural modification of the compound, which showed a relatively obvious proliferation inhibition effect on 95-D, Bel-7402, MDA-MB-231, PC-3 and HL-60 tumor cells with the IC50 value less than $15 \mu \mathrm{M}$ (determined in our lab), and was considered as a new antitumor drug candidate $[17,18]$. The further investigations of copen were funded by National Major Scientific and Technological Special Project for "Significant New Drugs Development" in China, Project No. 2011ZX09302-003-03.

Previous research in our team revealed that copen demonstrated good antitumor activity on 95-D, Bel-7402, MDA-MB-231, PC3 , and HL-60 tumor cells. In order to elucidate the mechanism of its pharmacological activity and toxicity, it's very necessary to investigate the pharmacokinetics of copen in vivo since limited data was available. Our previous study reported a quantification method for copen in rat plasma and its simple application [19], which was not enough for the illustration of the systematic pharmacokinetic behavior of copen in rats. Copen is presently undergoing preclinical study; therefore, it is necessary to evaluate the pharmacokinetics and oral bioavailability of copen for further development.

In the present study, the pharmacokinetics of copen after intragastrical and intravenous administration were systematically investigated using a LC-MS/MS method. Key pharmacokinetic issues, such as oral bioavailability and gender difference, would be well addressed in support of the further structural modification of osthole and copen.

\section{Materials and Methods}

\section{Chemicals and reagents}

Copen (purity $>99.5 \%$, Lot No. 20131210) was provided by Guangdong Zonk Drug R\&D Limited, and bicalutamide (purity $>99.3 \%$ ) was kindly provided by Zhejiang Institute for Food and Drug Control (Hangzhou, PR China) (Figure 1). Ultrapure water $(>18 \mathrm{~m} \Omega$ ) was obtained from a Milli-Q water purification system (Millipore, MA, USA). HPLC grade acetonitrile and methanol were purchased from Merck (Darmstadt, Germany). All other chemicals used were of analytical grade.

*Corresponding author: Shentu J, Research Centre for Clinical Pharmacy, State Key Laboratory for Diagnosis and Treatment of Infectious Diseases, First Affiliated Hospital, Zhejiang University, Hangzhou 310003, China, Tel: +86-571-87236537; Fax: +86-571-87214223; E-mail: youtai.1234@163.com

Received January 16, 2017; Accepted February 24, 2017; Published March 07 2017

Citation: Zheng Y, Zhou H, Hu X, Wu G, Yanan L, et al. (2017) Pharmacokinetics Analysis of Copen, a Novel Antitumor Semi Synthetic Derivative of Osthole, in Rats after Intragastric and Intravenous Administration. J Bioequiv Availab 9: 359-363. doi: 10.4172/jbb.1000325

Copyright: @ 2017 Zheng Y, et al. This is an open-access article distributed under the terms of the Creative Commons Attribution License, which permits unrestricted use, distribution, and reproduction in any medium, provided the original author and source are credited. 


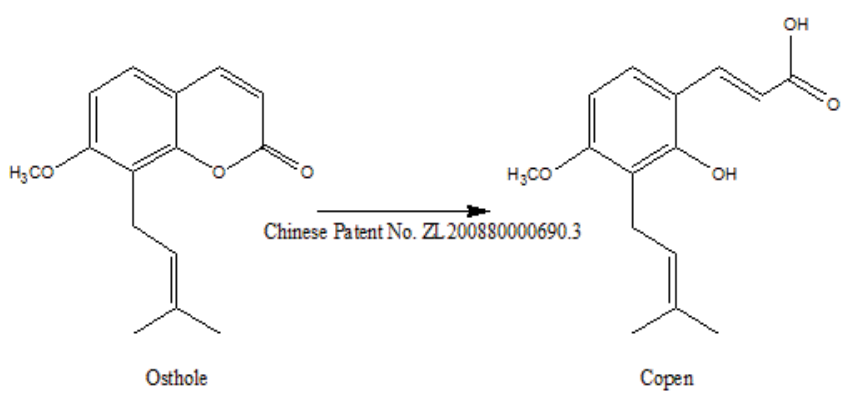

Figure 1: Chemical structures of copen and osthole.

\section{Animals}

Sprague-Dawley adult healthy rats (weighing $211 \pm 13 \mathrm{~g}$ ) both male and female were purchased from the Laboratory Animal Center of Zhejiang Academy of Medical Sciences (Hangzhou, China). Animals were raised under controlled conditions in the Institute for Experimental Animals, First Affiliated Hospital, Zhejiang University (temperature: 25 $\pm 2^{\circ} \mathrm{C}, 12 \mathrm{~h}$ light-dark cycle), for at least one week before experiment. All experiments performed in rats were in accordance with the P.R. China legislation on the use and care of laboratory animals and approved by Experimental Animal Ethical Committee, First Affiliated Hospital, Zhejiang University.

\section{Study design}

Seventy-six Sprague-Dawley rats, both male and female (211 $\pm 13 \mathrm{~g}$ ), were fed with standard laboratory food and water, and kept in an environmentally-controlled breeding room for six days before experimentation. Rats were fasted for $12 \mathrm{~h}$ and allowed free access to water prior to the experiments.

The rats were randomly divided into six groups and twelve rats (50\% male and $50 \%$ female) in each group. Three groups were given copen $(62.5 \mathrm{mg} / \mathrm{mL}$, dissolved in normal saline) intragastricly at doses of 25,50 and $100 \mathrm{mg} / \mathrm{kg}$, while the other three groups were given intravenously (through tail vein injection) at the same doses, respectively. The doses were confirmed according to the results from our previous in vivo tumor inhibition effect of copen in mice. Disposable sterilized syringes were used for intravenous administration and medical cotton ball was pressured on the wound until bloodless after injection. Blood samples (about $300 \mu \mathrm{L}$ ) were collected in heparinized $1.5 \mathrm{~mL}$ polythene tubes from the tail vein before and at 0, 5, 10, 15, 30, 60, 90, 120, 240, 360, 600 and $1440 \mathrm{~min}$ after intragastrical and intravenous administration. All blood samples were immediately centrifuged to separate plasma at 3000 $\mathrm{rpm}$ at $4^{\circ} \mathrm{C}$ for $10 \mathrm{~min}$. The plasma was transferred into clean tubes and stored at $-80^{\circ} \mathrm{C}$ until analysis.

\section{Copen analyses}

Plasma concentrations of copen were determined by using an LC-MS/MS method (Shimadzu LC-20AD system, Shimadzu, Tokyo, Japan) validated in our laboratory [19]. Copen and internal standard (bicalutamide) were separated on an Agilent ZorbaxSB-C18 column (4.6 $\times 100 \mathrm{~mm}, 1.8 \mu \mathrm{m}$, Agilent Technologies, CA, USA), using an isocratic mobile phase consisting of methanol $-5 \mathrm{mM}$ ammonium formate water with $0.1 \%$ formic acid $(80: 20, \mathrm{v} / \mathrm{v})$. Column temperature was maintained at $40^{\circ} \mathrm{C}$. The detection was performed on a triple-quadrupole tandem mass spectrometer (API 4000 triple-quadrupole mass spectrometer; $\mathrm{AB}$ Sciex, Ontario, Canada) by the multiple reactions monitoring mode via negative eletrospray ionization. The parent and daughter ions transitions were monitored at $\mathrm{m} / \mathrm{z} 261.2 \rightarrow 217.1$ for copen and at $\mathrm{m} / \mathrm{z}$ $429.0 \rightarrow 255.0$ for bicalutamide (IS). Two linear calibration curves were obtained in the concentration range of $0.052 \sim 20.6 \mu \mathrm{g} / \mathrm{mL}$ (using a 1/ $\mathrm{x} 2$ weighted least squares linear regression model) and $10.1 \sim 504.8 \mu \mathrm{g} /$ $\mathrm{mL}$ (using a $1 / \mathrm{x}$ weighted least squares quadratic regression model). The intraday and interday precision values (R.S.D\%) were within $15 \%$.

Dilution integrity was carried out in this study. The blank plasma samples spiked with $1010 \mu \mathrm{g} / \mathrm{mL}$ of copen (exceeding the upper limit of the calibration curve) were diluted by five-fold and subjected to LCMS/MS analysis. The experiments were conducted in six replicates. The dilution integrity was deemed acceptable when the precision and accuracy were within $\pm 15 \%$.

\section{Statistical analyses}

All experimental data and pharmacokinetic parameters are expressed as the means \pm Standard Deviation (SD). Peak plasma concentrations $\left(\mathrm{C}_{\max }\right)$ and the time to reach peak plasma concentrations $\left(\mathrm{T}_{\max }\right)$ were obtained directly from the observed concentration versus time data. Other pharmacokinetic parameters were estimated through the drug and statistics (DAS) software, version 2.1.1 (Shanghai, China). Bioavailability of different gender was calculated individually. Statistical analysis of the pharmacokinetic parameters was performed with SPSS 16.0 software using independent two-sample t-test, $\mathrm{p}$-values less than 0.05 were considered statistically significant.

\section{Results}

\section{Dilution integrity}

The concentration of copen in some plasma samples exceeded the upper limit of detection, therefore, these samples were diluted by fivefold in the same biological matrices prior to LC-MS/MS analysis. We determined the accuracy and precision of copen detection using diluted biological samples. The accuracy was between $96.4 \%$ and $105.6 \%$, and the precision was within $3.29 \%$ for samples diluted in plasma matrices. These results indicated that the concentration of copen in plasma could be determined with acceptable precision and accuracy using diluted samples.

\section{Sample analysis and quality control (QC)}

New linear calibration curves were constructed during every day's analyzing, and QC samples at six concentration levels $(0.052,1.65,16.5$ $\mu \mathrm{g} / \mathrm{mL}$ for the low concentration calibration and $4.04,40.4,404 \mu \mathrm{g} / \mathrm{mL}$ for the high concentration calibration, $n=2$ ) were analyzed at the same time. The results of QC samples all showed good precision and accuracy within the $15 \%$ acceptable range, which indicated the concentrations of copen determined in this study were reliable.

\section{Pharmacokinetic analysis}

Pharmacokinetics of copen in rats after intragastric administration: The mean plasma concentration-time curves of copen in rats after intragastric administration at doses of 25, 50 and $100 \mathrm{mg} /$ $\mathrm{kg}$ was shown in Figure 2. The main pharmacokinetic parameters of intragastric administrations were summarized in Table 1.

Pharmacokinetics of copen in rats after intravenous administration: After intravenous administration of copen at doses of 25,50 and $100 \mathrm{mg} / \mathrm{kg}$ to rats, the mean plasma concentration-time profiles of copen are shown in Figure 2. The main pharmacokinetic parameters after intravenous administration are listed in Table 2. 
Citation: Zheng Y, Zhou H, Hu X, Wu G, Yanan L, et al. (2017) Pharmacokinetics Analysis of Copen, a Novel Antitumor Semi Synthetic Derivative of Osthole, in Rats after Intragastric and Intravenous Administration. J Bioequiv Availab 9: 359-363. doi: 10.4172/jbb.1000325

Influence of gender on the pharmacokinetics of copen: The mean plasma concentration-time curves and pharmacokinetic parameters of copen in male and female rats after intragastric doses of copen are shown in Figure 3 and Table 3, respectively.

\section{Bioavailability and safety}

The absolute bioavailability (F\%) of copen was calculated by comparing the corresponding values of $\mathrm{AUC}_{0-\infty}$ from the intragastric (i.g) and intravenous (i.v) administration groups $(25,50$ and $100 \mathrm{mg} /$
$\mathrm{kg}):\left(\mathrm{F} \%=\left(\mathrm{AUC}_{\mathrm{i} . \mathrm{g}}\right) /\left(\mathrm{AUC}_{\mathrm{i} . \mathrm{v}}\right) \times 100 \%\right)$, and the results of the absolute bioavailability are shown in Table 4 . The results showed that intragastric administration of copen leads to an absolute bioavailability of $2.21 \sim$ $10.67 \%$. The absolute bioavailability in females was higher than that in males, especially for the high dose $(100 \mathrm{mg} / \mathrm{kg})$. This observation suggests that copen exhibited a better absorption property in females than in males, which was in agreement with the high AUC and $\mathrm{C}_{\max }$ estimates.
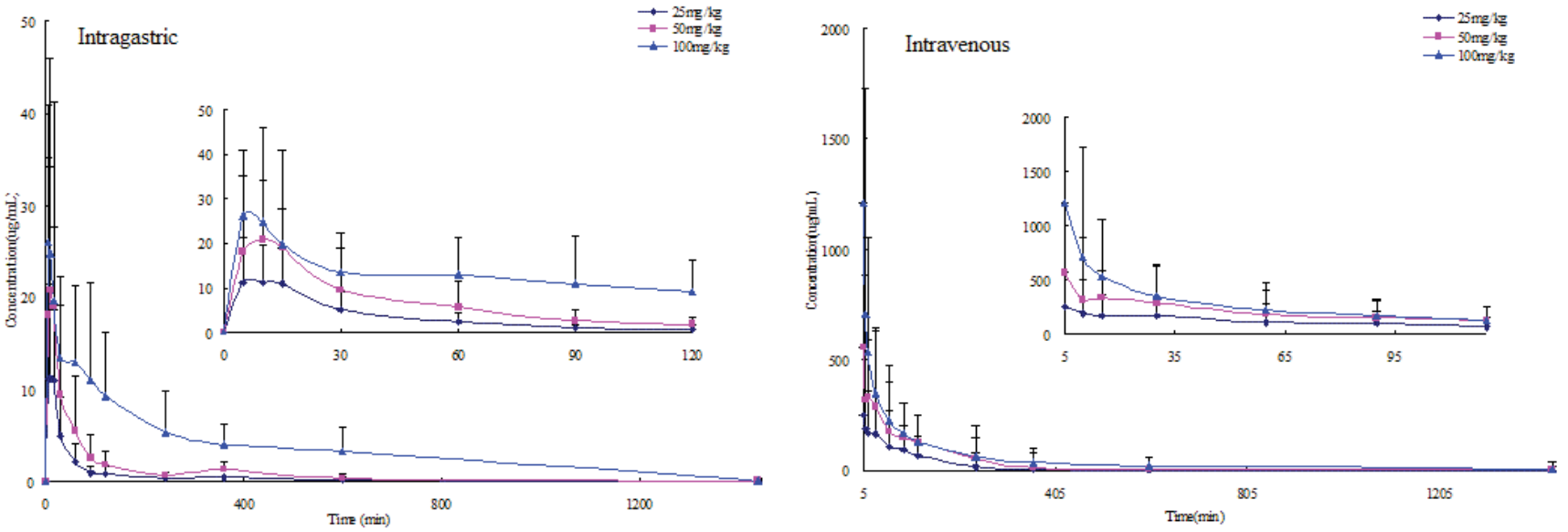

Figure 2: The mean plasma concentration-time curves of copen in rats after intragastric and intravenous doses of copen (25, 50 and $100 \mathrm{mg} / \mathrm{kg} ; \mathrm{n}=12)$.

\begin{tabular}{|c|c|c|c|}
\hline $\begin{array}{ll}\text { Parameters } & \text { Doses } \\
\end{array}$ & $25 \mathrm{mg} / \mathrm{kg}$ & $50 \mathrm{mg} / \mathrm{kg}$ & $100 \mathrm{mg} / \mathrm{kg}$ \\
\hline$A U C_{0 . t}(\mathrm{mg} / \mathrm{L} \mathrm{min})$ & $729.59 \pm 437.80$ & $1468.60 \pm 920.76$ & $5167.31 \pm 2842.48$ \\
\hline$A U C_{0 . \infty}(m g / L ~ m i n)$ & $1018.02 \pm 421.57$ & $1546.33 \pm 957.81$ & $5708.30 \pm 10770.80$ \\
\hline $\mathrm{MRT}_{0-\mathrm{t}}(\mathrm{min})$ & $199.84 \pm 108.14$ & $215.88 \pm 135.95$ & $292.55 \pm 80.53$ \\
\hline $\mathrm{MRT}_{0 . \infty}(\min )$ & $305.00 \pm 208.98$ & $264.41 \pm 151.59$ & $409.51 \pm 368.18$ \\
\hline$t_{1 / 2 z}(\min )$ & $302.16 \pm 169.90$ & $243.80 \pm 112.71$ & $196.55 \pm 66.44$ \\
\hline$T_{\max }(\min )$ & $10.00 \pm 3.69$ & $9.17 \pm 3.59$ & $14.17 \pm 24.01$ \\
\hline $\mathrm{CLz} / \mathrm{F}(\mathrm{L} / \mathrm{min} / \mathrm{kg})$ & $0.046 \pm 0.027$ & $0.049 \pm 0.031$ & $0.025 \pm 0.016$ \\
\hline $\mathrm{C}_{\max }(\mathrm{mg} / \mathrm{L})$ & $13.39 \pm 10.17$ & $21.96 \pm 25.84$ & $28.35 \pm 10.24$ \\
\hline
\end{tabular}

Table 1: Pharmacokinetic parameters of copen after intragastric administration of 25,50 and $100 \mathrm{mg} / \mathrm{kg}(\mathrm{n}=12$, mean \pm SD).

\begin{tabular}{|c|c|c|c|}
\hline $\begin{array}{ll} & \text { Doses } \\
\text { Parameters } & \\
\end{array}$ & $25 \mathrm{mg} / \mathrm{kg}$ & $50 \mathrm{mg} / \mathrm{kg}$ & $100 \mathrm{mg} / \mathrm{kg}$ \\
\hline$A U C_{0 . t}(\mathrm{mg} / \mathrm{L} \mathrm{min})$ & $24545.80 \pm 21102.82$ & $54342.71 \pm 76451.41$ & $68653.62 \pm 37177.46$ \\
\hline 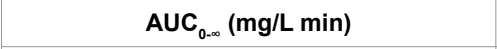 & $24813.01 \pm 21056.08$ & $57579.07 \pm 81167.16$ & $83932.17 \pm 60623.48$ \\
\hline $\mathrm{MRT}_{0 . \mathrm{t}}(\min )$ & $82.90 \pm 54.72$ & $111.83 \pm 57.71$ & $122.012 \pm 62.79$ \\
\hline $\mathrm{MRT}_{0-\infty}(\min )$ & $199.53 \pm 348.08$ & $138.60 \pm 87.58$ & $235.61 \pm 375.14$ \\
\hline$t_{1 / 2 z}(\min )$ & $236.49 \pm 101.77$ & $258.07 \pm 110.36$ & $229.05 \pm 110.11$ \\
\hline$T_{\max }(\min )$ & $5.00 \pm 0.0$ & $5.00 \pm 0.0$ & $5.00 \pm 0.0$ \\
\hline CLz (L/min/kg) & $0.007 \pm 0.009$ & $0.003 \pm 0.003$ & $0.003 \pm 0.005$ \\
\hline$C_{\max }(\mathrm{mg} / \mathrm{L})$ & $338.34 \pm 290.40$ & $553.68 \pm 539.87$ & $1451.58 \pm 1108.34$ \\
\hline
\end{tabular}

Table 2: Pharmacokinetic parameters of copen after intravenous administration of 25,50 and $100 \mathrm{mg} / \mathrm{kg}(\mathrm{n}=12, \mathrm{mean} \pm \mathrm{SD})$. 

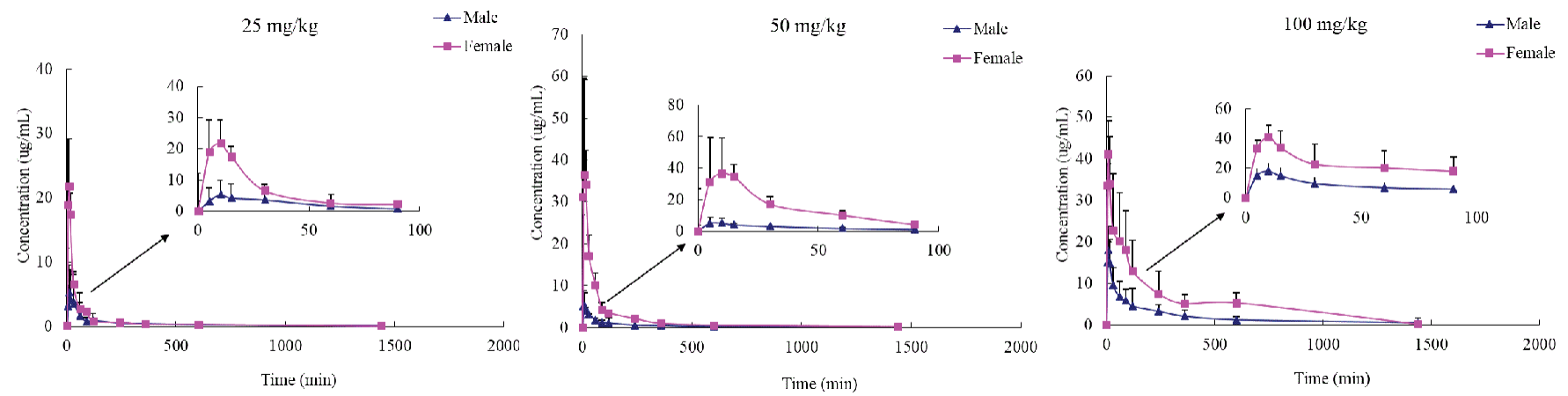

Figure 3: The mean plasma concentration-time curves of copen in male and female rats after intragastric doses of copen (25, 50 and $100 \mathrm{mg} / \mathrm{kg} ; \mathrm{n}=6)$.

\begin{tabular}{|c|c|c|c|c|c|c|c|}
\hline \multirow{2}{*}{ Gender } & \multirow{2}{*}{ Doses } & \multicolumn{6}{|c|}{ Parameters } \\
\hline & & $\mathrm{AUC}_{0 . \mathrm{t}}(\mathrm{mg} / \mathrm{L} \mathrm{min})$ & 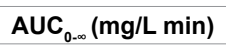 & $t_{1 / 2 z}(\min )$ & $T_{\max }(\min )$ & $\mathrm{CLz} / \mathrm{F}(\mathrm{L} / \mathrm{min} / \mathrm{kg})$ & $C_{\max }(\mathrm{mg} / \mathrm{L})$ \\
\hline \multirow{3}{*}{ Male } & $25 \mathrm{mg} / \mathrm{kg}$ & $570.16 \pm 532.90$ & $517.17 \pm 504.41$ & $364.20 \pm 200.12$ & $10.83 \pm 3.76$ & $0.048 \pm 0.024$ & $5.79 \pm 4.67$ \\
\hline & $50 \mathrm{mg} / \mathrm{kg}$ & $726.83 \pm 337.32$ & $770.38 \pm 383.57$ & $276.91 \pm 133.51$ & $8.33 \pm 4.08$ & $0.074 \pm 0.022$ & $5.41 \pm 3.74$ \\
\hline & $100 \mathrm{mg} / \mathrm{kg}$ & $2917.47 \pm 1082.43$ & $2939.62 \pm 1065.02$ & $173.58 \pm 70.11$ & $6.67 \pm 2.58$ & $0.037 \pm 0.011$ & $19.40 \pm 4.82$ \\
\hline \multirow{3}{*}{ Female } & $25 \mathrm{mg} / \mathrm{kg}$ & $889.01 \pm 276.92$ & $1518.86 \pm 286.24$ & $240.11 \pm 119.23$ & $9.17 \pm 3.76$ & $0.032 \pm 0.017$ & $20.98 \pm 8.20^{*}$ \\
\hline & 50 mg/kg & $2210.37 \pm 656.25^{*}$ & $2322.29 \pm 652.76^{*}$ & $210.70 \pm 86.57$ & $10.00 \pm 3.16$ & $0.023 \pm 0.007^{*}$ & $38.52 \pm 28.23^{*}$ \\
\hline & $100 \mathrm{mg} / \mathrm{kg}$ & $7417.15 \pm 2110.77^{*}$ & $8476.98 \pm 3691.84^{*}$ & $219.52 \pm 59.41$ & $21.67 \pm 33.57$ & $0.012 \pm 0.008^{*}$ & $37.30 \pm 3.88^{*}$ \\
\hline
\end{tabular}

*Indicates statistical significance $(p<0.05)$.

Table 3: Pharmacokinetic parameters of copen in male and female rats after intragastric doses of copen (25, 50 and $100 \mathrm{mg} / \mathrm{kg} ; \mathrm{n}=6)$.

\begin{tabular}{|c|c|c|c|}
\hline Rats sex & F \% (25 $\mathbf{~ m g / k g )}$ & $\mathbf{F}$ \% (50 $\mathbf{~ m g / k g )}$ & F \% (100 $\mathbf{~ m g / k g ) ~}$ \\
\hline Male & 3.51 & 2.21 & 3.32 \\
\hline Female & 4.35 & 2.89 \\
\hline
\end{tabular}

Table 4: Absolute bioavailability of copen in female and male rats $(n=6)$.

Throughout the study, no died rat was found. However, after intragastrical and intravenous administration, all the rats' tails appeared different degrees of necrosis, especially the site of injection, which indicated that copen have obvious skin toxicity.

\section{Discussion}

After intragastric administration of copen, the absorption of copen from the rat gastrointestinal tract was discovered rapidly. Copen was detected in the plasma from the first blood sampling time (5 min) and rapidly reached $\mathrm{T}_{\max }(9.2-14.2 \mathrm{~min})$. It is worthy of noting that the spearman's rank correlation coefficient ( $\mathrm{rs}$ ) of $\mathrm{C}_{\max }$-Dose was $0.49810(\mathrm{p}=0.0023)$, and the rs of $\mathrm{AUC}_{0-\mathrm{t}}$-Dose was $0.74634(\mathrm{p}<0.0001)$, indicating a positive correlation between $\mathrm{C}_{\max }$ or $\mathrm{AUC}_{0-\mathrm{t}}$ and intragastric doses.

After intravenous administration of copen, the elimination halflives $\left(t_{1} / 2_{z}\right)$ were assessed to be $236.49 \pm 101.77,258.07 \pm 110.36$ and $229.05 \pm 110.11 \mathrm{~min}$ at doses of 25,50 and $100 \mathrm{mg} / \mathrm{kg}$ to rats, respectively. It indicated that copen has a long dwell time in rat with a long elimination half-life (about $4 \mathrm{~h}$ ). Total clearance (CLz) of copen was estimated to be $0.003 \sim 0.007 \mathrm{~L} / \mathrm{min} / \mathrm{Kg}$ among the doses tested (Table 2). The spearman's rank correlation coefficient (rs) of $\mathrm{C}_{\max }$ Dose was $0.64171(\mathrm{p}<0.0001)$, and the rs of $\mathrm{AUC}_{0-\mathrm{t}}$-Dose was 0.64337 $(\mathrm{p}<0.0001)$, which also showed strong positive correlation between $\mathrm{C}_{\max }$ or $\mathrm{AUC}_{0-\mathrm{t}}$ and intravenous doses.

As big SD were observed for most of the parameters in Table 1 and
Table 2, the differences of gender on copen's absorption or distribution were analyzed. The results showed that significant differences $(\mathrm{p}<0.05)$ of $\mathrm{AUC}_{0-\mathrm{t}}, \mathrm{AUC}_{0-\infty}, \mathrm{CLz} / \mathrm{F}$ and $\mathrm{C}_{\max }$ were present in female and male groups after intragastric doses $(50$ and $100 \mathrm{mg} / \mathrm{kg}$ ). The results suggested that copen possessed more favorable absorption properties in females than in males, as the values of AUC and $\mathrm{C}_{\max }$ were more than 2-fold higher in females than in males. The mechanism of this phenomenon needs further studies to be clarified.

Compared with the $\mathrm{AUC}_{0-\infty}$ in rats after intravenous and intragastric administration of copen at doses of 25,50 and $100 \mathrm{mg} / \mathrm{kg}$, the absolute bioavailability were $4.10 \%, 2.69 \%, 6.80 \%(\mathrm{n}=12)$, respectively, which were lower than that of osthole $(\mathrm{F} \%=15.65 \%)$, indicating the lactone hydrolysis could not help osthole improving its bioavailability. Further structure modification must be carried out based on copen or osthole, so as to improve their bioavailability and reduce their toxicity.

\section{Conclusion}

This is the first study on the investigation of absolute bioavailability, pharmacokinetics, and gender difference of copen. Positive correlation between $\mathrm{C}_{\max }$ or $\mathrm{AUC}_{0-\mathrm{t}}$ and doses were noted. The long half time (229.05 $258.07 \mathrm{~min}$ ) indicates that the elimination of copen is not rapid. Significant gender differences were observed in pharmacokinetic behaviors of copen in rats after intragastric administration, as females performed much better absorption properties than males. Furthermore, the absolute bioavailability of copen in male and female rats was estimated as $2.21 \sim 10.67 \%$. The presence of obvious gender difference 
Citation: Zheng Y, Zhou H, Hu X, Wu G, Yanan L, et al. (2017) Pharmacokinetics Analysis of Copen, a Novel Antitumor Semi Synthetic Derivative of Osthole, in Rats after Intragastric and Intravenous Administration. J Bioequiv Availab 9: 359-363. doi: 10.4172/jbb.1000325

in absorption properties and skin toxicity may have an impact on the further structure modification of osthole and copen, and should be considered into the development of therapeutic regimens.

\section{Acknowledgment}

This research was funded by the National Natural Science Foundation of China (No. 81402807), the Doctoral Fund of the Ministry of Education of China (No. 20130101120136).

\section{References}

1. Zhang XY, Xiang RD (1997) Research of chemical components of Cuidium monnieri (L.) cusson. Chinese Tradit Herb Drug 28: 588-590.

2. Commission of the Chinese Pharmacopoeia (2010) Chinese Pharmacopoeia Part I, Chemical Industry Press, Beijing, pp: 295-296.

3. Yang D, Gu T, Wang T, Tang Q, Ma C (2010) Effects of osthole on migration and invasion in breast cancer cells. Biosci Biotechnol Biochem 74: 1430-1434.

4. Zhang LR, Jiang GR, Yao F, He Y, Liang GQ, et al. (2012) Growth inhibition and apoptosis induced by osthole, a natural coumarin, in hepatocellular carcinoma. PLoS One 7: e37865.

5. Xu XM, Zhang Y, Qu D, Jiang TS, Li SQ (2011) Osthole induces G2/M arrest and apoptosis in lung cancer A549 cells by modulating PI3K/Akt pathway. Am $\mathrm{J}$ Clin Cancer Res 30: 33-37.

6. Xu XM, ZhangY, Qu D, Feng XW, Chen Y, et al. (2012) Osthole suppresses migration and invasion of A549 human lung cancer cells through inhibition of matrix metalloproteinase-2 and matrix metallopeptidase-9 in vitro. Mol Med Rep 6: 1018-1022.

7. Kao SJ, Su JL, Chen CK, Yu MC, Bai KJ, et al. (2012) Osthole inhibits the invasive ability of human lung adenocarcinoma cells via suppression of NFkappa B-mediated matrix metalloproteinase-9 expression. Toxicol Appl Pharmacol 261: 105-115.

8. Lin VC, Chou CH, Lin YC, Lin JN, Yu CC, et al. (2010) Osthole suppresses fatty acid synthase expression in HER2-overexpressing breast cancer cells through modulating Akt/mTOR pathway. J Agric Food Chem 58: 4786-4793.

9. Liang HJ, Su FM, Wang CK, Hung LF, Liu DZ, et al. (2009) Osthole, a potential antidiabetic agent, alleviates hyperglycemia in $\mathrm{db} / \mathrm{db}$ mice. Chem Biol Interact 181: 309-315.

10. Song F, Xie T, Bao JJ, Xie ML (2006) Studies on hypolipidemic effects of osthole in rats. Suzhou Univ J Med Sci 26: 579-581.

11. You L, An R, Wang X, Li Y (2010) Discovery of novel osthole derivatives as potential anti-breast cancer treatment. Bioorg Med Chem Lett 20: 7426-7428.

12. You L, Feng S, An R, Wang X (2009) Osthole: a promising lead compound for drug discovery from a traditional Chinese medicine (TCM). Nat Prod Commun 4: 297-302.

13. Tsai TH, Tsai TR, Chen CC, Chen CF (1996) Pharmacokinetics of osthole in rat plasma using high-performance liquid chromatography. J Pharmaceut Biomed Anal 14: 749-753.

14. Li Y, Meng F Xiong Z, Liu H, Li F (2005) HPLC determination and pharmacokinetics of osthole in rat plasma after oral administration of Fructus Cnidii extract. J Chromatogr Sci 43: 426-429.

15. An F, Wang SH, Zhang DS, Zhang L, Mu JX (2003) [Pharmacokinetics of osthole in rabbits]. Yao Xue Xue Bao 38: 571-573.

16. Gao YR, Zhang L, Zhang DS (2005) The preparation of inclusion complex of osthole and determination of bioavailability in rabbit. Chinese Journal Hospital Pharmacy 25: 1143-1146.

17. Wang W, Ying J, Chen WZ, Liu XB, Xu K, et al. Chinese Patent No. ZL2008800006903.

18. Wang W, Ying J, Chen WZ, Liu XB, Xu K, et al. (2006) PCT Patent Application No. CN2008/001089.

19. Zhou HL, Zheng YL, Liu YN, Hu XJ, Wu GL, et al. (2014) Quantification of an antitumor agent (copen) in rat plasma by liquid chromatography-electrospray ionization tandem mass spectrometry and its application in a preclinical pharmacokinetics study. Biomed Chromatogr 29: 975-980. 